\title{
Visión a futuro de los mecanismos alternativos de solución de controversias
}

Future vision for alternative dispute resolution mechanisms

José de Jesús Orozco Henríquez*

Constituye un alto y grato honor participar en este evento académico para celebrar e vigésimo quinto aniversario de la Comisión Nacional de Arbitraje Médico (CONAMED), al lado de tan connotados y respetados expertos comprometidos con la protección del derecho humano a la protección de la salud.

En sus primeros 25 años, la CONAMED ha acreditado un avance sustancial en credibilidad y confianza entre la sociedad en general y el gremio médico en particular, así como en la consolidación institucional para garantizar de manera efectiva a sus usuarios el derecho humano a la protección de la salud y contribuir tanto a la dignificación de la profesión médica como a la mejora de la calidad de los servicios de salud.

Importante ha sido también su contribución para la instalación de instituciones similares en 28 entidades federativas, en las cuales se han homologado procedimientos y mecanismos alternativos de solución de controversias en materia de salud a favor de la ciudadanía, lo cual ha permitido configurar un modelo de mediación, conciliación y arbitraje médico en nuestro país. Como afirma Archibald Cox, para garantizar de manera efectiva los derechos humanos, es menester «multiplicar los lugares a los cuales un ciudadano puede recurrir en busca de desagravio a las ofensas que le fueron inferidas».

Al constituirse en una institución de vanguardia única en su tipo, tanto en el ámbito nacional como en el internacional, la CONAMED se ha caracterizado por la aplicación de mecanismos alternativos para la solución de controversias surgidas en los servicios de atención médica, tanto públicos como privados, a partir de los conocimientos generados por su actividad sustantiva; así como a través de proyectos de investigación específicos, ha contribuido a la prevención de conflictos derivados del acto médico, la mejora de la seguridad de los pacientes, sus familiares y en general a la construcción de una política pública de acceso efectivo a servicios de salud de calidad.

Vaya pues nuestra entusiasta felicitación a todos y cada uno de los destacados médicos y defensores de derechos humanos que la han dirigido, reconociéndoles a través de los comisionados nacionales Dr. José Meljem Moctezuma y Dr. Onofre Muñoz Hernández, quienes dignamente presidieron el Consejo de la CONAMED cuando tuve el privilegio de formar parte de él, al igual que al calificado personal que labora en la Comisión, por su profesionalismo, diligencia y compromiso. También eminentes fueron el resto de mis colegas en ese Consejo, en donde confluyeron notables académicas, académicos y profesionales de la medicina y el derecho, incluyendo expertos de la calidad del doctor David Kershenobich (por citar solo uno), de quienes mucho aprendí e hicieron importantes contribuciones a los trabajos de la CONAMED.
* Instituto de Investigaciones Jurídicas de la Universidad Nacional Autónoma de México. México.

Correspondencia: $\mathrm{JJOH}$, jorozcoh@unam.mx Conflicto de intereses: Sin conflicto de intereses. Citar como: Orozco HJJ. Visión a futuro de los mecanismos alternativos de solución de controversias. Rev CONAMED. 2021; 26(4): 179-181. https://dx.doi. org/10.35366/102505

Financiamiento: No hubo financiamiento.

Recibido: 26/10/2021. Aceptado: 26/10/2021. 
Uno de los factores que determinaron su creación en 1996 fue la creciente judicialización de los conflictos derivados del acto médico y la consecuente carga excesiva en las agencias del Ministerio Público y los tribunales por asuntos relacionados con la responsabilidad profesional de las y los médicos. Esta tendencia, que se originó en otros países, pero se había extendido a México, generó una enorme inquietud entre los profesionales de la salud, al sentirse amenazados por la expansión de la llamada «industria del litigio médico», lo cual dio lugar a una práctica médica «defensiva», con efectos negativos en la calidad técnica de la atención, el incremento significativo de sus costos y la falta de apego a la lex artis médica. Lo anterior propició un deterioro en las relaciones del personal de salud con las y los pacientes, así como con sus familiares a partir de una desconfianza creciente entre ambas partes.

De ahí que las autoridades sanitarias hayan impulsado la utilización de mecanismos alternativos para la atención de controversias derivadas del acto médico, mediante la creación de la CONAMED, como organismo especializado en la materia, con autonomía técnica y de gestión, así como garantías de imparcialidad y confidencialidad de los asuntos bajo su conocimiento, además de ventajas sobre los órganos y procedimientos jurisdiccionales ordinarios gracias a la evaluación realizada por expertos en materia médica y jurídica; su carácter gratuito, no confrontativo, flexible, respetuoso, personalizado, transparente, menos formalista y de buena fe, la mayor celeridad y eficacia en la conclusión, y su bajo costo económico.

Del análisis de la doctrina científica, las propuestas programáticas oficiales de diversos países (considerablemente de la región latinoamericana) y distintos ejercicios legislativos, se observa que, con énfasis desde finales del siglo pasado, los mecanismos alternativos de solución de controversias (a los que me referiré como MASC en lo sucesivo) han venido siendo propuestos o adoptados legalmente como una opción institucional de acceso, mejoramiento y modernización de la justicia. Se les concibe en una relación complementaria, mas no sustitutiva, de la función judicial, que contribuye a la descongestión de los tribunales y facilita la obtención de justicia.

En este sentido, por ejemplo, entre las conclusiones y recomendaciones que adoptó la III
Reunión de Ministros de Justicia o Procuradores Generales de las Américas para ser elevadas a la Asamblea General de la OEA durante su XXX Periodo Ordinario de Sesiones, celebrado en el año 2000 en Windsor, Canadá, reiteró su «compromiso con el mejoramiento del acceso a la justicia de los habitantes de los Estados Miembros de la Organización a través de la promoción y el uso de métodos alternativos de solución de conflictos».

Por lo que se refiere a nuestro país, si bien a nivel legislativo ya se contemplaban diversos MASC (por ejemplo: en las leyes federales sobre procedimiento administrativo, procedimientos civiles, amparo, responsabilidad patrimonial del Estado, trabajo, materia agraria y protección y defensa del usuario de servicios financieros), además de lo previsto en el mencionado decreto de creación de la CONAMED en 1996, no fue sino hasta junio de 2008 que el cuarto párrafo del Artículo 17 Constitucional estableció de manera expresa «Las leyes preverán mecanismos alternativos de solución de controversias».

De especial trascendencia fue la reforma constitucional de 2011 en materia de derechos humanos que, entre otras relevantes innovaciones, elevó a nivel constitucional los derechos humanos de fuente internacional. Asimismo, estableció la obligación de todos los servidores públicos, tanto federales como locales, de promover, respetar, proteger y garantizar el derecho a la protección de la salud consagrado a nivel constitucional desde 1984.

En consecuencia, el Estado (incluida la CONAMED) deberá preveniry, en su caso, reparar las violaciones al derecho humano a la protección de la salud, de conformidad con los principios de universalidad, interdependencia, indivisibilidad y progresividad, a plicando los estándares más altos que protejan de la manera más amplia a la persona, ya sea que éstos provengan de fuente nacional o internacional. Incluso, en el supuesto de que haya alguna norma interna que sea incompatible con un estándar internacional más alto, ejercer el control de convencionalidad a fin de inaplicar aquella en el caso concreto y preferir la norma de fuente internacional, teniendo en cuenta que, según jurisprudencia de la Corte Interamericana de Derechos Humanos, dicho control de la convencionalidad no solo debe ser ejercido ex officio por el poder judicial, sino por todos los órganos 
vinculados con la administración de justicia, como es el caso de la CONAMED.

A 25 años de la acreditación en la práctica de la idoneidad, eficacia y eficiencia de los MASC en el ámbito de la salud a cargo de la CONAMED, y de las diversas comisiones estatales equivalentes, así como a poco más de la mitad de ese periodo de la reforma que constitucionalizó los mecanismos alternativos para la solución de controversias en nuestro país, es imperativo que se incorporen en la Ley General de Salud los procedimientos de mediación, conciliación y arbitraje en el ámbito de la salud y se fortalezcan y amplíen las atribuciones de la CONAMED a fin de proporcionar un fundamento jurídico más sólido que brinde mayor estabilidad institucional y a sus usuarios una solución imparcial, efectiva, eficiente y oportuna, que tutele el derecho humano a la protección de la salud con pleno respeto de los derechos del personal médico y contribuya a la mejora de la calidad de los servicios de salud.

Además de la consecuente visibilidad de los MASC en materia de salud a cargo de la CONAMED que acarrearía el proceso legislativo y la entrada en vigor de la reforma correspondiente, a fin de mejorar y ampliar el acceso expedito de toda la población a este servicio, es importante promover entre los integrantes del sistema nacional de salud campañas de difusión con información actualizada que oriente y auxilie acerca de los propios MASC y los derechos con que cuentan tanto los usuarios del servicio como los prestadores del mismo, además de dotar a la CONAMED de los recursos necesarios para cumplir su alta misión ante el previsible incremento de casos bajo su conocimiento.

Ciertamente, la positiva experiencia de la CONAMED ha demostrado la idoneidad de los MASC, particularmente en el ámbito de la salud y la gran importancia que tiene que la evaluación (ya sea en los procedimientos de mediación, conciliación o arbitraje) sea realizada por expertos en la materia para determinar la calidad del servicio médico y, en consecuencia, la eventual responsabilidad profesional, así como para otorgar una mayor seguridad legal a los usuarios y prestadores de servicios de salud a través de la prueba pericial.

Es relevante mencionar que en el modelo de arbitraje, además de la emisión de laudos que resuelven acerca de la responsabilidad médica en el caso concreto, se considera también la emisión de opiniones técnicas que establecen apreciaciones y recomendaciones necesarias para el mejoramiento de la calidad en la atención médica, especialmente en los asuntos que revisten interés general. Estas opiniones técnicas a cargo de la CONAMED pueden estar dirigidas a las autoridades, corporaciones médicas y prestadores de servicios médicos que revisten la mayor importancia, pues pueden traducirse en una vía para transitar de la atención curativa, que predomina en el Sistema Nacional de Salud en vigor, a la indispensable atención preventiva y mejora estructural en el ámbito de la salud.

Es igualmente importante salvaguardar el carácter tutelar de la CONAMED y cuidar (como ha sostenido uno de sus primeros consejeros, el ilustre maestro Sergio García Ramírez) que los procedimientos que lleva a cabo no se transformen en prácticas burocráticas o dilatorias y, por tanto, eliminar las eventuales interferencias del poder en la justicia y las desviaciones que puedan reproducir las desigualdades sociales existentes, teniendo en cuenta la presencia de dos partes asimétricas en conocimiento médico, escolaridad y grupo social, pues, de lo contrario, se corre el riesgo del abandono de estos mecanismos y, en consecuencia, la reproducción de los obstáculos al acceso a la justicia de los excluidos del sistema formal. Incluso, cabría ponderar que, tal y como ocurre con la Comisión Coahuilense de Conciliación y Arbitraje Médico, se defina y estructure a la CONAMED como organismo público autónomo.

Es claro que también debe reforzarse la coordinación y homologación de los procedimientos de las comisiones de mediación, conciliación y arbitraje en las entidades federativas, así como los vínculos de colaboración con la Comisión Nacional de los Derechos Humanos, a fin de contribuir a la mejora de la calidad de los servicios de salud y, especialmente, a garantizar de manera efectiva el derecho humano a la protección de la salud, cuyo principio central e inmutable que lo sustenta es la dignidad humana; eje rector y valor fundamental de todo Estado constitucional democrático de derecho.

Muchas gracias y felicidades. 